\title{
Prevalence of malocclusions in school-age children attending the orthodontics department of Shiraz University of Medical Sciences
}

\author{
M. Oshagh, ${ }^{1}$ F. Ghaderi, ${ }^{2}$ H.R. Pakshir ${ }^{7}$ and A.M. Baghmollai ${ }^{3}$
}

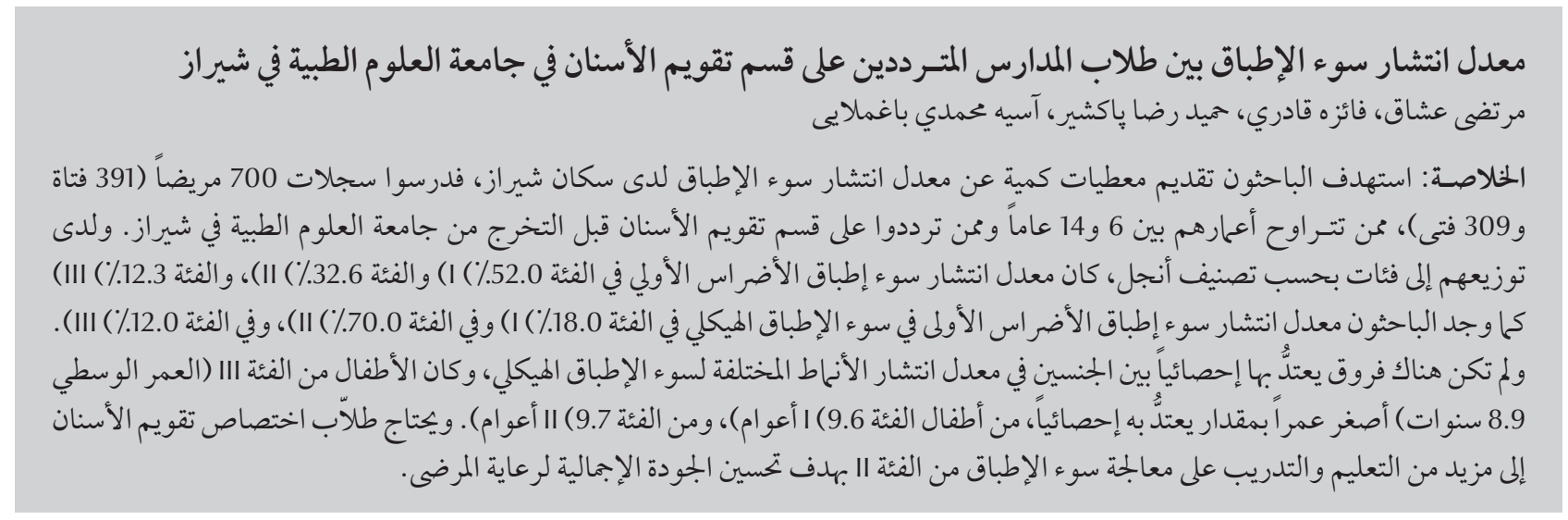

ABSTRACT To provide quantitative data about the prevalence of malocclusions in the Shiraz orthodontic population, we studied the records of 700 patients (391 girls and 309 boys) aged 6-14 years attending the undergraduate Department of Orthodontics at Shiraz University of Medical Sciences. The prevalence of Angle class I, II and III malocclusion of first molars was 52.0\%, 32.6\% and 12.3\% respectively. Skeletal class I, II and III malocclusion was found in $18.0 \%, 70.0 \%$ and $12.0 \%$ respectively. There were no significant differences between the sexes in the prevalence of different types of skeletal malocclusion. Children with class III were significantly younger (mean age 8.9 years) than those with class I (9.6 years) or class II (9.7 years) malocclusions. Orthodontics students need more education and training in the management of class II malocclusion to improve the overall quality of care for patients.

Prévalence des malocclusions chez les enfants d'âge scolaire en consultation dans le service d'orthodontie de l'Université des Sciences médicales de Shiraz (République islamique d'Iran)

RÉSUMÉ Pour fournir des données quantitatives sur la prévalence des malocclusions dans la population orthodontique de Chiraz, nous avons étudié les dossiers médicaux de 700 patients (391 filles et 309 garçons), âgés de six à quatorze ans ayant consulté dans le service d'orthodontie du premier cycle de l'Université des Sciences médicales de Shiraz. La prévalence des malocclusions des premières molaires correspondait respectivement à 52,0 \% des patients pour la classe I, à 32,6 \% pour la classe II et à 12,3 \% du groupe étudié pour la classe III, selon la classification d'Angle. La prévalence des malocclusions squelettiques de classe I correspondait respectivement à 18,0 \% des patients, celle de la classe II à 70,0 \% et celle de la classe III à 12,0\% du groupe étudié. II n'y avait pas de différences significatives entre les sexes pour la prévalence des types de malocclusion squelettique. Les enfants ayant une malocclusion de classe III étaient nettement plus jeunes (âge moyen 8,9 ans) que ceux qui présentaient une malocclusion de classe I (9,6 ans) ou de classe II (9,7 ans). Les étudiants en orthodontie ont besoin d'un enseignement et d'une formation renforcés pour la prise en charge des malocclusions de classe II afin d'améliorer la qualité globale des soins aux patients.

${ }^{7}$ Orthodontic Research Centre, Department of Orthodontics; ${ }^{2}$ Department of Pedodontics, Faculty of Dentistry, Shiraz University of Medical Sciences, Shiraz, Islamic Republic of Iran (Correspondence to M. Oshagh: morteza_oshagh@yahoo.com).

${ }^{3}$ Dental Practice, Shiraz, Islamic Republic of Iran.

Received: 14/03/09; accepted: 27/05/09 


\section{Introduction}

The prevalence of malocclusion has been reported for different populations, but the figures can vary widely, even for the same population. Variables such as differences in the classification of malocclusions, age of the study sample, examiner differences in determining normal occlusion, and differences in sample sizes can affect the results [1].

Although several studies have investigated the prevalence of dentofacial characteristics in a given population, few studies have been conducted among patients who seek or are referred for orthodontic care [1-10]. Danaei et al. reported that in Shiraz, Islamic Republic of Iran, the prevalence of class I, II and III malocclusions in schoolchildren aged 7-9 years was $47.4 \%, 14.7 \%$ and $2.1 \%$ respectively [11]. Hedayati et al. found that almost half of the 11-14year-old schoolchildren in Shiraz had a slight need or no need for orthodontic treatment according to the index of orthodontic treatment need [12]. In another study, however, they concluded that $70.1 \%$ of $12-15$-year-old students in Shiraz had normal or minor malocclusions, indicating no need for orthodontic treatment [13].

No representative data on the prevalence of dentofacial characteristics are available for the orthodontic population in Shiraz. Because the number of orthodontists available to treat patients in Shiraz is only about 15, there is a high demand on each practitioner for treatment. Moreover, the establishment of a service usually leads to increased demand for treatment and there has been a steady increase in the number of patients being referred for treatment. Clearly the evaluation of referred patients and the distribution of malocclusion types can provide valuable information for planning an orthodontic service. The present study was therefore designed to determine the frequency of malocclusions in a population of patients attending a university department of orthodontics in Shiraz for orthodontic treatment.

\section{Methods}

The orthodontic records of 700 patients (391 girls and 309 boys) attending the Department of Orthodontics at Shiraz University of Medical Sciences were selected randomly from 1200 patients and retrieved from the archives for evaluation.

Patients with a history of previous orthodontic treatment or with systematic disease, craniofacial deformities or syndrome and patients with incomplete records were excluded from this study. All patients were from the southern regions of the Islamic Republic of Iran and none of them had undergone previous orthodontic treatment. Information about social class or ethnic origin was not recorded in the patient records at the department of orthodontics. Almost all patients were self-referred since there is no formal referral system for dental care through the Iranian health service. In addition, the insurance system in the country provides almost no special coverage for orthodontic treatment.

Written case records, dental casts, panoramic and cephalometric X-rays and intraoral and extraoral photographs were studied. The following dentofacial characteristics were investigated from initial records: molar relation according to Angle's classification and skeletal relationaccordingto ANB andWit's appraisal, overjet, overbite, crossbite, growth pattern and oral habits $[14,15]$. Lateral cephalometric X-rays were retrieved and traced to establish skeletal relations. Skeletal malocclusion and growth pattern were determined by measuring SNA (saddle-nasion-A-point angle), SNB (saddle-nasion-B-point angle), ANB (A point-nasion-B-point angle), Wit's distances, Go-Gn-SN (goniongnathion-saddle-nasion angle) and FMA (Frankfort plan-mandibular plan angle). Non-nutritional habits (thumb sucking, pacifier sucking, pen or nail biting, lip sucking or cheek biting) were determined by questioning children and their parents. Other characteristics were determined by clinical examination.

The data were pooled and analysed with the chi-squared test and 1-way analysis of variance. All analyses were done using SPSS, version 8.

\section{Results}

The overall ratio of boys to girls was approximately $4: 5$. The age distribution of patients is shown in Figure 1. The age

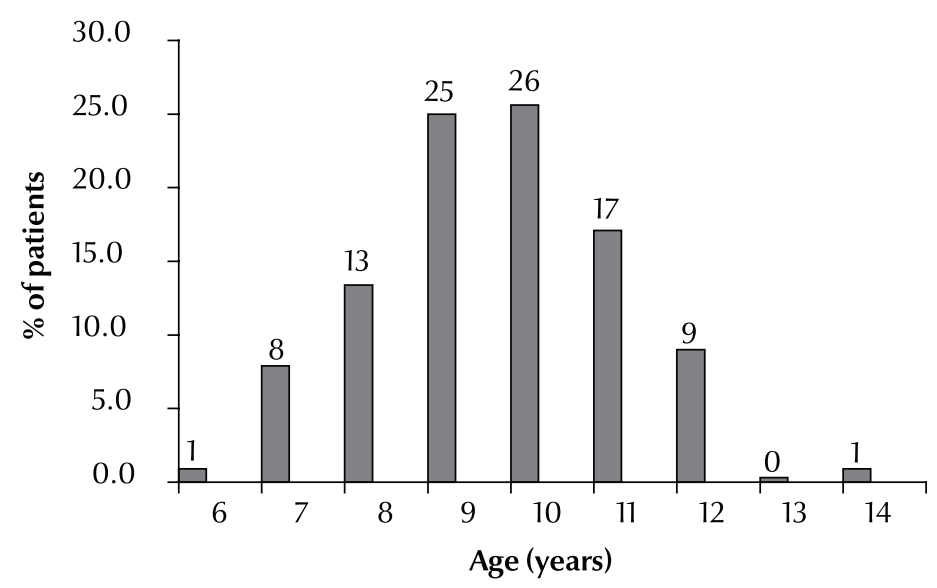

Figure 1 Age distribution of paediatric patients attending Shiraz University of Medical Sciences orthodontics department 


\begin{tabular}{|c|c|c|c|c|c|c|c|}
\hline \multirow[t]{2}{*}{ Variable } & \multicolumn{2}{|c|}{$\begin{array}{c}\text { Total } \\
(n=700)\end{array}$} & \multicolumn{2}{|c|}{$\begin{array}{c}\text { Boys } \\
(n=309)\end{array}$} & \multicolumn{2}{|c|}{$\begin{array}{c}\text { Girls } \\
(n=391)\end{array}$} & \multirow[t]{2}{*}{$\begin{array}{c}P \text {-value } \\
\text { (boys vs girls) }\end{array}$} \\
\hline & No. & $\%$ & No. & $\%$ & No. & $\%$ & \\
\hline \multicolumn{8}{|l|}{ Malocclusion (skeletal) } \\
\hline Class I & 126 & 18.0 & 54 & 17.5 & 70 & 17.9 & 0.25 \\
\hline Class II & 490 & 70.0 & 224 & 72.5 & 270 & 69.1 & \\
\hline Class III & 84 & 12.0 & 31 & 10.0 & 51 & 13.0 & \\
\hline Malocclusion (Angle class) & & & & & & & 0.06 \\
\hline Class I & 364 & 52.0 & 147 & 47.6 & 217 & 55.5 & \\
\hline Class II & 228 & 32.6 & 105 & 34.0 & 123 & 31.5 & \\
\hline Class III & 86 & 12.3 & 48 & 15.5 & 38 & 9.7 & \\
\hline End-to-end & 22 & 3.1 & 9 & 2.9 & 13 & 3.3 & \\
\hline Growth pattern & & & & & & & 0.71 \\
\hline Normal & 168 & 24.0 & 77 & 24.9 & 91 & 23.3 & \\
\hline Vertical & 396 & 56.6 & 169 & 54.7 & 227 & 58.1 & \\
\hline Horizontal & 136 & 19.4 & 62 & 20.1 & 74 & 18.9 & \\
\hline Overjet & & & & & & & $<0.001$ \\
\hline Normal & 364 & 52.0 & - & - & - & - & \\
\hline Large & 210 & 30.0 & - & - & - & - & \\
\hline Negative & 126 & 18.0 & - & - & - & - & \\
\hline Bite type & & & & & & & 0.46 \\
\hline Normal & 252 & 36.0 & 102 & 33.0 & 160 & 40.9 & \\
\hline Deep bite & 371 & 53.0 & 170 & 55.0 & 215 & 55.0 & \\
\hline Open bite & 77 & 11.0 & 37 & 12.0 & 46 & 11.8 & \\
\hline Cross bite & 252 & 36.0 & 115 & 37.2 & 137 & 35.0 & 0.17 \\
\hline \multicolumn{8}{|l|}{ Other } \\
\hline Oral habits & 119 & 17.0 & 51 & 16.5 & 68 & 17.4 & 0.08 \\
\hline
\end{tabular}

at first consultation ranged from 6-14 years but almost all (97.9\%) were in the age range $7-12$ years.

The prevalence of skeletal class I, II and III malocclusion was $18.0 \%$, $70.0 \%$ and $12.0 \%$ respectively, and there was no significant difference between the sexes in the prevalence of skeletal malocclusion $(P=0.25)$ (Table 1$)$. The mean age of patients with skeletal class III malocclusion [8.9 (SD 1.5) years] was significantly lower than patients with class I [9.6 (SD 1.5) years] or class II malocclusions [9.7 (SD 1.4) years] $(P<0.001)$.

Table 1 also shows the distribution of malocclusion in both sexes according to Angle's classification of first molars. The prevalence of Angle class I malocclusion was $52.0 \%$, class II $32.6 \%$ and class III $12.3 \%$. There were some differences in the prevalence of Angle malocclusion between the sexes but these were not statistically significant $(P=0.06)$. However, among all class III patients the percentage of girls (44.2\%) was significantly lower than boys (55.8\%) $(P<0.05)$ (Table 1).

The growth pattern was normal in $24.0 \%$ of children, vertical in $56.6 \%$ and horizontal in $19.4 \%$, and there was no significant difference in growth patterns between the sexes $(P=0.71)$.

The prevalence of large overjet was $30.0 \%$ and negative overjet was $18.0 \%$. The rate of overjet was significantly higher in boys than girls $(P<0.001)$ (Table 1). However, there were no significant differences in the prevalence of different overbites between the sexes $(P$
$=0.46)$. Crossbite was found in $36.0 \%$ of the sample (17.0\% anterior and $19.0 \%$ posterior crossbite). Oral habits were noted in $17.0 \%$ of patients, including thumb sucking in $9.2 \%$ and lip biting in $2.0 \%$. No significant difference was found in the prevalence of crossbite $(P=0.17)$ or oral habits $(P=0.08)$ between the sexes.

\section{Discussion}

In this study of Iranian children who sought orthodontic treatment, the prevalence of class I, II and III malocclusion of first molars was 52.0\%, 32.6\% and $12.3 \%$ respectively. The reported prevalence of dental malocclusion in a Colombian study of young patients varied from $39 \%$ to $93 \%$ [16]. The prevalence 
of different types of malocclusion may show considerable variability, even in a population of the same origin. The criteria for normality vary from one examiner to another, and this affects the results of different studies. Our data are in agreement with Sari et al., who reported that $61.7 \%$ of the patients in Turkey had class I, $28.1 \%$ had class II and $10.2 \%$ had class III Angle dental malocclusion [17]. Small differences between different sets of results may be related to sample selection, ethnic origin and sample size. The sample analysed by Sari et al. consisted of patients accepted for treatment, whereas our sample consisted of the total referred population [17].

Our results are also very similar to those of Jones, who investigated dental malocclusion in 132 Saudi Arabian patients referred for orthodontic treatment and reported that $53.8 \%$ had class I, $33.3 \%$ class II and $12.9 \%$ had class III Angle dental malocclusions [7]. However, these results might not represent the prevalence of malocclusion in the reference population because the sample size was insufficient.

Our findings show less agreement with Sayin and Türkkahraman's study, which found that the prevalence of class I, II and III Angle dental malocclusions in a Turkish population referred for orthodontic treatment was $64 \%, 24 \%$ and $12 \%$ respectively [1]. Although their reported frequency of class I and II malocclusions was different from our results, the frequency of class III malocclusion was similar. However, a study in Indonesia obtained different figures for class III frequencies, reporting a $2 \%$ incidence in the Indonesian sample compared to 4\% in an English sample and 23\% in a Chinese population [5].

The male:female ratio in our study was $4: 5$, which is similar to the $4: 6$ ratio in the studies by Willems et al. [18], Jones [7] and Sayin and Türkkahraman [1]. In our study $48.0 \%$ of the patients had abnormal (class II or III) molar interdigitation. This is in agreement with a 2007 study onstudents in Shiraz, which found deviation from the class I molar relation in about half the sample [13].

The data from our orthodontic population was affected by selection bias and cannot be extrapolated to the whole Shiraz population. Therefore, our patients would be expected to have a greater prevalence of malocclusion. Similarly, Ucuncu and Ertugay found that $83.2 \%$ of the Turkish patients referred for treatment, but only $38.3 \%$ of the school-aged population, had a great need for orthodontic treatment [10]. In another study Danaei et al. found that in 7-9-year-old children in Shiraz, the prevalence of class I, II and III malocclusion was $47.4 \%, 14.7 \%$ and $2.1 \%$ respectively [11]. The lower prevalence of class II and III malocclusion in their study may be related to sample selection, as noted above. Nevertheless, the orthodontic population can be a useful group for analyses related to specific orthodontic treatments, as others have previously reported $[8,9,19,20]$.

Although Angle's classification has been the topic of many discussions in the literature $[21,22]$, it remains a fairly easy and accurate way of categorizing malocclusions, and is widely used in the dental profession. We therefore used Angle's original classification in this study to categorize dental malocclusions. The results of this categorization are shown in Table 2, and compared with those of other surveys $[8,9,19,20,23]$. It is nonetheless difficult to compare prevalence studies of dentofacial characteristics because the results represent different ethnic types [18].

The type of malocclusion is an important factor that affects a patient's motivation to seek treatment [1]. In our study, comparisons of the mean ages of the malocclusion groups indicated a statistically significant difference between skeletal class III and other groups, and the lowest mean age was in the class III group (8.9 years). This contrasts with Wilmont et al.'s study, which reported that patients with a severe sagittal class II deformity had a higher motivation for orthodontic treatment [24]. This may be attributed to the fact that in Iranian society, a slightly convex profile in young children is more acceptable than concave profiles. Adolescence is often associated with increased selfconsciousness, confusion about identity and acceptance by others, and concerns about recognition from adults and peers [25]. Accordingly, adolescents are more likely to be highly motivated to seek orthodontic treatment. According to our results, the majority of patients were 7-12 years old. Thus (and while acknowledging that external motivations may also play a role) we can conclude that the motivation for orthodontic

\begin{tabular}{|c|c|c|c|c|c|c|c|}
\hline \multirow[t]{3}{*}{ Angle class } & Present study & $\begin{array}{c}\text { Willems et al. } \\
\text { [18] }\end{array}$ & Beresford [23] & $\begin{array}{c}\text { Sheiham et al. } \\
{[19]}\end{array}$ & Rose [8] & Vig et al. [20] & Yang [9] \\
\hline & $\begin{array}{c}\text { Islamic Republic } \\
\text { of Iran }\end{array}$ & Belgium & England & England & England & USA & Korea \\
\hline & $\%$ & $\%$ & $\%$ & $\%$ & $\%$ & $\%$ & $\%$ \\
\hline Class I & 52.0 & 31 & 37.8 & 47.1 & 49.2 & 43.7 & 53.9 \\
\hline Class II & 35.6 & 63 & 60.4 & 44.3 & 46.3 & 50.8 & 14.9 \\
\hline Class III & 12.3 & 6 & 1.8 & 8.6 & 4.5 & 5.5 & 49.1 \\
\hline
\end{tabular}


treatment increased during early adolescence in our Iranian population sample. However, this interpretation must take into consideration the fact that at the Shiraz orthodontic department, most patients older than 12 years attend the postgraduate section of the department, and those records were not reviewed in the present study.

In our study skeletal class II patients comprised the greatest percentage of cases, but in Danaei et al.'s study the prevalence of class II malocclusion in the Shiraz population was only $14.7 \%$ [11]. This suggests that more class II patients in our population were referred for orthodontic treatment. It therefore seems logical to reinforce education and training about class II malocclusion for Iranian dental students. Moreover, our results suggest that insurance system coverage for these patients would be appropriate.

In our sample of children the prevalence of skeletal class I, II and III malocclusions was 18\%, 70\% and 12\% respectively. These figures differ from those of Jones, who reported $46.4 \%$ for class I, 27.5\% for class II and 26.1\% for class III skeletal malocclusion in Saudi Arabian patients [7]. This difference may be attributed to ethnic differences and the small size of the Saudi Arabian study sample.

In our study, $56.5 \%$ of the patients had a vertical growth pattern of the facial skeleton, compared with Willem's study, which reported $29 \%$ vertical growth pattern at a Belgian university [18]. On the other hand our study showed that 19\% of our sample had posterior crossbite, similar to the prevalence of this anomaly in Willem's study (15\%) [18].

The prevalences of large overjet (30.0\%), negative overjet (18,0\%) and open bite (11.0\%) were higher than in a study by Danaei et al., which reported prevalences of increased overjet of $17 \%$, reverse overjet of less than $2 \%$ and open bite of less than 3\% [13]. These differences can also be attributed to the fact that their sample consisted of a random selection of schoolchildren rather than referred patients and to the older age in general of the students in their study compared to our sample.

\section{Conclusions}

Most of the children attending the Department of Orthodontics at this Shiraz hospital had skeletal class II malocclusion. Since the number of orthodontists available to treat patients in the city of Shiraz is limited, there is a high demand on each practitioner for treatment. Therefore current orthodontics students should receive more education and training in the management of class II malocclusion to improve the overall quality of care for patients.

\section{Acknowledgements}

This study was supported by the Office of the Vice Chancellor for Research of Shiraz University of Medical Sciences.

We thank the Centre for Development of Clinical Research of Nemazee Hospital in Shiraz for editorial assistance and K. Shashok (AuthorAID in the Eastern Mediterranean) for improving the use of English in the manuscript.

\section{References}

1. Sayin MO, Türkkahraman H. Malocclusion and crowding in an orthodontically referred Turkish population. Angle Orthodontist, 2004, 74:635-639.

2. Brunelle JA, Bhat M, Lipton JA. Prevalence and distribution of selected occlusal characteristics in the U.S. population, 1988-91. Journal of Dental Research, 1996, 75:706-7013.

3. Foster TD, Day AJ. A survey of malocclusion and the need for orthodontic treatment in a Shropshire school population. British Journal of Orthodontics, 1973, 1:73-78.

4. Ingervall B. Prevalence of dental and occlusal anomalies in Swedish conscripts. Acta Odontologica Scandinavica, 1974, 32:83-92.

5. Johnson JS, Soetamat A, Winoto NA. A comparison of some features of the Indonesian occlusion with those of two other ethnic groups. British Journal of Orthodontics, 1978, 5:183-188.

6. Proffit WR, Fields HW, Moray LJ. Prevalence of malocclusion and orthodontic treatment need in the United States: estimates from the NHANES 3 survey. International Journal of Adult Orthodontics and Orthognathic Surgery, 1998, 13:97-106.

7. Jones BW. Malocclusion and facial types in a group of Saudi Arabian patients referred for orthodontic treatment: a preliminary study. British Journal of Orthodontics, 1987, 14:143-146.

8. Rose JS. A thousand cases: a survey. British Journal of Orthodontics, 1974, 1:45-54.
9. Yang WS. [The study on the orthodontic patients who visited department of orthodontics, Seoul, National University Hospital]. Taehan Chikkwa Uisa Hyophoe Chi, 1990, 28:811-821 [in Korean].

10. Uçüncü N, Ertugay E. The use of the index of orthodontic treatment need (IOTN) in a school population and referred population. Journal of Orthodontics, 2001, 28(1):45-52.

11. Danaie SM, Asadi Z, Salehi P. Distribution of malocclusion types in 7-9-year-old Iranian children. Eastern Mediterranean Health Journal, 2006, 12(1-2):236-240.

12. Hedayati Z, Fattahi HR, Jahromi SB. The use of index of orthodontic treatment need in an Iranian population. Journal of the Indian Society of Pedodontics and Preventive Dentistry, 2007, 25(1):10-14.

13. Danaei SM, Amirrad F, Salehi P. Orthodontic treatment needs of 12-15 year old students in Shiraz, Islamic Republic of Iran. Eastern Mediterranean Health Journal, 2007, 13(2): 326-234.

14. Angle EH. Classification of malocclusion. Dental Cosmos, 1908, 41:248-264.

15. Proffit WR, Fields HWJr, Sarver DM, eds. Contemporary orthodontics, 4th ed. St Louis, Missouri, Mosby, 2007:195-199.

16. Thilander B et al. Prevalence of malocclusion and orthodontic treatment need in children and adolescents in Bogota, Colombia. An epidemiological study related to different stages of 
dental development. European Journal of Orthodontics, 2001, 23:153-168.

17. Sari Z et al. Orthodontic malocclusions and evaluation of treatment alternatives: an epidemiologic study. Turkish Journal of Orthodontics, 2003, 16:119-126.

18. Willems $\mathrm{G}$ et al. Prevalence of dentofacial characteristics in a Belgian orthodontic population. Clinical Oral Investigations, 2001, 5: 220-226.

19. Sheiham A et al. Orthodontic treatment in the general dental service in England and Wales: a study. British Dental Journal, 1971, 131:535-538.

20. Vig PS et al. The duration of orthodontic treatment with and without extractions: a pilot study of five selected practices. American Journal of Orthodontics and Dentofacial Orthopaedics, 1990, 97:45-51.
21. Brin I, Weinberger T, Ben-Choirin E. Classification of occlusion reconsidered. European Journal of Orthodontics, 2000, 22:169-174.

22. Du SQ et al. Reliability of three methods of occlusion classification. American Journal of Orthodontics and Dentofacial Orthopaedics, 1998, 113(4):463-470.

23. Beresford JS. Tooth size and class distinction. Dental Practice, 1969, 20:113-120

24. Wilmont JJ et al. Associations between severity of dentofacial deformity and motivation for orthodontic-orthognathic surgery treatment. Angle Orthodontist, 1993, 63:283-288.

25. Tung AW, Kiyak HA. Psychological influences on the timing of orthodontic treatment. American Journal of Orthodontics and Dentofacial Orthopaedics, 1998, 113:29-39.

\section{Hidden cities: unmasking and overcoming health inequities in urban settings}

This global report is an important component of the overall World Health Organization strategy to strengthen the response of the local, national and global health communities to reduce health inequities in an increasingly urbanized world.

The report exposes the extent to which the urban poor suffer disproportionately from a wide range of diseases and health problems, which can be traced back to inequalities in their social and living conditions. It also provides evidencebased information and tools to help municipal and health authorities tackle health inequities in their cities.

The case for action is juxtaposed with personal stories and photos illustrating the issues of urban health equity in six countries. Stories of municipal and national authorities who are taking action to reduce inequities also are featured.

Further information about this and other WHO publication is available at: http://www.who.int/publications/en/ 